\title{
Part and Parcel: A qualitative interview study examining the experience of client rudeness by mental health workers
}

\begin{abstract}
Considerable research has demonstrated that workplace rudeness can have a variety of negative consequences. However, although research has examined the impact of patient aggression, no research has examined patient or client rudeness towards those who work in mental health roles. The present study investigated the nature of client rudeness, how mental health workers respond and the coping strategies used. Eighteen participants from a range of mental health roles and experience levels participated in semi-structured interviews based on their experience of client rudeness. Thematic analysis revealed that participants experienced a variety of client behaviours they classified as rude, the majority of which were verbal. Reasons for rudeness included the client's personal history, mood, and mental health, and as such rudeness was conceptualised as simply a part of the job. Client rudeness was found to have both negative and positive outcomes on a range of areas including work and client relationships. Participants identified supervisors and colleagues as key sources of support for coping with rudeness. These findings suggest that rudeness is 'part and parcel' of a mental health practitioner's role. Supervisor support and further training are recommended to help practitioners deal with rudeness in practice.
\end{abstract}

Keywords: Incivility; rudeness; mental health; coping 


\section{Introduction}

Workplace incivility can be found at the low end of the scale of workplace abuse, defined by Andersson and Pearson (1999, p. 457) as "low-intensity deviant behaviour with ambiguous intent to harm the target, in violation of workplace norms of mutual respect". These behaviours, demonstrating a lack of regard for fellow workers, can include sarcasm, untidiness and abruptness. While these acts are seemingly minor and without obvious malice, the negative impact on both victims and witnesses has been extensively documented (Schilpzand, De Pater, \& Erez, 2016). Persistent rudeness or incivility at work has been linked to several negative outcomes including employee burnout, increased quitting intention (Han, Bonn, \& Cho, 2016), higher levels of stress (Adams \& Webster, 2013), reduced motivation (Sakurai \& Jex, 2012) and absenteeism (Sliter, Sliter, \& Jex, 2012). These outcomes have associated monetary costs for organisations; estimated to be approximately $\$ 14,000$ per employee in the USA (Pearson \& Porath, 2009).

In order to understand this behaviour Andersson and Pearson (1999) proposed a social interactionist view of rudeness centred on a dyad composed of instigator and victim. This theory suggests that incivility is a social interaction that involves the instigator, the target, any observers and the social context. The behaviours experienced in the interaction have the potential to escalate, with the possibility of future aggression as a result (forming an incivility spiral). Within the interaction the characteristics of each individual and the environment in which the interaction takes place have the capacity to influence the behaviours shown. Central to this theory is the idea that incivility is a behaviour that shows disregard for workplace norms regarding politeness, civility and expectations about professional behaviour. As such, the authors are suggesting that there will be constraints on behaviour, depending on the situation, with some behaviours considered more appropriate in one context than another. 
The aim of this study was to explore the experience of rudeness in the specific environment of mental health work. Mental health presents a unique context where social norms of behaviour may be suspended, or ignored, as patients and clients go through the therapeutic process. As such, the perception of rudeness, and the response of the counsellor or therapist, is likely to be specific to this context.

\section{The therapeutic relationship}

Mental health professionals and volunteers can work in a variety of settings, from responding to patients via telephone and email helplines, to operating within private practice, to working on an inpatient psychiatric ward. In each case the practitioner establishes a relationship with the patient or client, with the aim of engaging in supportive therapeutic practices (Shattell, Starr, \& Thomas, 2007). Research examining patient perception of this relationship suggests that patients look for security and empathy, and need to trust their therapist (Horberg, Brunt, \& Axelsson, 2004). Shattell and colleagues (2007) gathered data on the therapeutic relationship from individuals interacting with social workers, counsellors, physicians and psychologists. The results indicated that there were three key aspects to the therapeutic relationship. First, participants wanted to feel connected to the practitioner, often through empathy, sympathy and non-judgemental listening. Second, there was the perception that therapy needed to be specific to the individual, with the patient recognised as a person rather than a diagnosis. Finally, there was a stated need for therapy to have an end goal or a solution to a problem. Participants noted that if these elements were not achieved there was a capacity for anger and frustration, potentially leading to an adverse relationship (Shattell et al., 2007).

Hill and Knox (2009) reviewed the literature on the therapeutic relationship and suggest that there are several problems that can arise during therapy. These range from dealing with hostile clients who are disengaged from the process, to managing 
misunderstandings and disagreements. Anger can also be an issue and can be generated by negative perceptions of therapist's actions or might arise from client-specific circumstances (e.g. homelessness, abuse, substance use, past trauma. Hill \& Knox, 2009; Dalenberg, 2004). Mental health professionals therefore need to be prepared to deal with a range of emotions and behaviours from their clients or patients, which may include aggression and rudeness.

\section{Aggression in mental health}

There is a lack of research examining rudeness within mental health settings, but there has been a great deal of research conducted to examine patient aggression. Although aggression is a more intense behaviour than incivility, this research can still provide useful insight into difficult patient behaviours and potential causal factors for patient rudeness. Research suggests that patients with serious mental ill health (e.g. schizophrenia, major depression, or bipolar disorder) may be more likely to be violent (being involved in fights, perhaps involving a weapon) than those without such a diagnosis (Swanson, 1994). This suggests that in some cases of serious mental illness, aggression is a risk to staff, which is further demonstrated by research investigating the experiences of psychiatric nurses. Nijman, Bowers, Oud, and Jansen (2005) and Jonker, Goossens, Steenhuis, and Oud (2008) report that psychiatric nurses experience verbal abuse, threats, and sexual harassment or intimidation frequently.

In order to try and understand the potential causes of patient aggression in mental health settings three key explanatory theories have been put forward; internal, external and interactional (Duxbury \& Whittington, 2005). The internal model suggests that aggression is directly linked to mental illness, particularly where the patient also engages in substance abuse. The external model suggests that inpatient settings, such as the design of the ward or the lack of privacy, may induce aggression in patients as a reaction to their environment. Finally, the interactional model suggests that a negative or unpleasant relationship between 
staff and patients may lead to aggression (Duxbury \& Whittington, 2005). However, the majority of the research underlying these models was conducted in the context of inpatient psychiatric wards or institutions. There is a lack of research examining the potential causes of patient aggression and rudeness in outpatient settings, such as within the community or in private practice, therefore it is unclear if the models detailed above could be generalised across different mental health contexts.

The consequences of aggressive incidents in psychiatric care can be serious and carry significant psychological outcomes for staff (Inoue, Tsukano, Muraoka, Kaneko, \& Okamura, 2006), including post-traumatic stress disorder symptoms, guilt, shame, anger, fear, and anxiety (Needham, Aberhalden, Halfens, Fischer, \& Dassen, 2005). This clearly demonstrates that the severity of such incidents extends beyond any physical injuries. Indeed, nurses in a study by Kristiansen, Hellzen and Asplund (2006) were unsure of how long they could endure aggression and rudeness from patients. Not only does aggression affect nurses, but the nurse's reaction to aggression can be detrimental to the patient themselves. For example, Khalil (2009) found that mental health nurses classified aggressive patients as 'bad' patients, and consequently these patients were seen as being a lower priority for treatment and care, resulting in less timely treatment, poorer quality of treatment or the patient being ignored. These attributions occurred in the context of a severe shortage of nursing staff.

\section{Incivility in mental health}

Insight into the impact of rudeness on mental health professionals may be drawn from work examining 'difficult' patients within mental health care. Typically difficult patients present as demanding, high volume users of care with behaviours ranging from aggression and rudeness to failure to comply with treatment (Koekkoek, Hutschemaekers, van Meijel, \& Schene, 2011). Similarly to patient aggression, healthcare professionals explain difficult behaviours as caused by neurological conditions, psychotic disorders, socio-economic inequities or 
internal characteristics (e.g., poor coping skills or character) (Koekkoek et al., 2011). The proposed cause of difficult behaviours was linked to the response from healthcare teams; if difficult behaviours were thought to relate to illness the behaviours were accepted. However, if difficulty was thought to be due to patient character, support may be withdrawn, the patient might be ignored, and treatment may suffer (Koekkoek et al., 2011). Several authors suggest an association between borderline personality disorder (BPD) and the label of 'difficult', with BPD patients considered destructive, aggressive, rule breaking and manipulative (Sulzer, 2015). These patients are described at risk of being 'routed out of care' as professionals seek to pass the patient on to other providers. However, this research considers 'difficulty' as a construct of a variety of behaviours, arguably with no core characteristics (Koekkoek, van Meijel, \& Hutschemaekers, 2006), and as such it is unclear to what extent rudeness or incivility in isolation might be perceived and impact mental health professionals.

From the workplace research discussed above, it is clear that the impact of incivility is pervasive and damaging to its targets. Furthermore, research suggests that difficult and aggressive patients are considered problematic within mental healthcare, with adverse consequences for both patients and staff. The current study aims to expand on these areas of research by investigating client rudeness in mental health. The term 'client' has been chosen as it represents the terminology used by the majority of participants. Additionally, the decision was made to use the terms 'incivility' and 'rudeness' interchangeably, as participants were more familiar with the latter.

Using a qualitative design, the study will attempt to obtain an overall picture of client rudeness from the perspective of those in mental health-related and emotionally supportive roles. The critical incident technique (Flanagan, 1954) has been used to investigate experiences of aggression within healthcare previously (Irwin, Laing \& Mearns, 2013), and 
will serve as the framework for semi-structured interviews with participants in a range of mental health roles. The study aimed to address the following research questions:

$\mathrm{R}^{1}$ : How is client incivility perceived by mental health professionals?

$\mathrm{R}^{2}$ : What is the impact of client incivility?

$\mathrm{R}^{3}$ : How do mental health professionals respond to client incivility?

$\mathrm{R}^{4}$ : How do mental health professionals cope with client incivility?

\section{Method}

\section{Participants}

A total of 18 participants (14 female) were recruited from across the United Kingdom, with the majority from North East Scotland. Participants met eligibility requirements if they held emotionally supportive or mental health roles, either professionally or as volunteers, if they had experienced rudeness from clients in their role, and if they worked outside the NHS in the role they would discuss. The criterion of having experienced rudeness was included as the aim was to describe rudeness rather than to estimate its prevalence. One participant's role encompassed both NHS and private work, and it was requested that they discuss only their private work. Any NHS information they discussed was removed from the interview transcript. The roles held were varied, as the intention of the study was to gather a broad sample (see Table 1).

\section{Table 1 here.}

It should be noted that there was some variation within categories, for example, one counsellor specialised in perinatal mental health and thus occupied a different client base to other general adult mental health counsellors.

Participants were initially recruited via direct email, with contact details drawn from organisation websites and counselling directories. The invite email outlined the aim of the 
study, detailed the method used, and invited the receiver to contact the main researcher if they were willing to take part in the study.

\section{Interviews}

Each interview began by outlining the type of work the participant was involved in.

Following this a framework of questions around which to base the semi-structured interviews was developed from the critical incident technique (Flanagan, 1954), with the intention of obtaining rich information in response to the four research questions:

- Incivility incidents: To identify the type of incivility that participants face from clients, and collect information on particular examples, e.g. "Have you experienced incivility from a client? If so, can you give me an example?"

- Reactions: To identify how participants respond to client incivility, e.g. "How do you feel people in your role should react to rude clients?"

- Effect: To assess the impact of client incivility on the participant, their relationship with the client, and on their work, e.g. "How do you think incivility impacts any treatment you give?"

- Coping: To identify what participants do to mitigate any negative impact of client incivility and what is provided to assist them, e.g. "What kind of support do you receive to help you cope?"

Spontaneous follow-up questions were also asked in each interview where further detail was required.

\section{Data collection}

Interviews were conducted face to face at the participant's place of work, or over the phone. They ranged from 8 to 56 minutes in length. Prior to the interview, participants were told that they could decline to answer any question posed to them, and could stop the interview at any time. Interviews were recorded using an Olympus digital voice recorder. Interviews were 
then transcribed from the audio recordings, at which point the original recordings were deleted and any identifying information in the transcripts were removed, ensuring the anonymity of all participants. Twelve initial interviews of the total were conducted and analysed first, after which point six further interviews were conducted in order to both gain a broader range of roles and achieve data saturation. Data saturation, the point at which no new themes were being generated on the basis of additional interviews (Guest, Bunce, \& Johnson, 2006), was reached at interview number 16, with the final two interviews conducted to gain additional job roles within the sample.

\section{Data analysis}

Interviews were analysed using inductive thematic analysis. This has been identified as an adaptable and useful method of analysing qualitative data (Braun \& Clarke, 2006). Information concerning participants' roles was not analysed as this was gathered in order to categorise their work, and create an informal start to the interview. The remainder of the interview transcripts were coded in three main phases by the first author. Initial codes describing the data at a semantic level were developed. These codes were discussed by the first and second co-authors to ensure they provided a detailed and relevant representation of the data. The codes were then grouped into initial themes linked to the main research questions. The initial themes were reviewed and refined by all of the co-authors in order to ensure each theme was valid and represented a coherent pattern of data (Braun \& Clarke, 2006). The resulting themes are presented below, organised according to the relevant research question.

\section{Results}

A variety of examples of incivility were identified by participants, as seen in Table 2. Many were recalled as specific incidents, although some were more general examples of incivility that they had experienced. 


\section{Table 2 here}

The majority of incidents involved verbal behaviour, the most common being complaints about the treatment by the participant:

"She was kind of like “Well it's your fault, you don't really listen, you talk to us, you know, the same, you don't really care", and it's just kind of refuting those statements, trying to explain that we do." -P9

Direct verbal rudeness, in which statements were unrelated to treatment, were also common: "I've had "You're a snob, you don't understand, you're a snob"-P6 Inappropriate joking was reported as a mechanism for being rude:

"He had this joke, at first he was like "Oh, you're gonna [sic] make my tea, like you're my tea fetcher" -P4

Avoidance and resisting participation refer to clients not attending sessions or cancelling at short notice, and declining to be involved in activities while in the session respectively.

Misleading was also discussed, which involved the client presenting themselves to the participant as less capable than they actually were:

"The client was - argued that they were unable to control their language, which I subsequently found out was not true" -P12

\section{Perception of client incivility}

As seen in Table 3, a wide variety of causes for client rudeness were offered by participants. The most popular of these was the client's personal history, including negative events, their upbringing, and harmful relationships:

“Some people have been very badly hurt in the past, they've not been-they've always been let down, you know, maybe some of the more chaotic families that we support, they've got a history of being able to-not being able to communicate in a [n] articulate way or an assertive way but maybe in quite an aggressive way. "-P1 
Table 3 here.

Participants stated the client's mental health could be an important factor, either making it difficult for the client to control their behaviour, or creating behaviours that appear rude:

"You know, if somebody for instance has some kind of social difficulty or social anxiety or social disorder, then you know that will then manifest through how they interact, how they're able to interact and that could very well be taken as rude." $-P 3$

Factors relating to the relationship between the client and the participant were also noted as important. As such, participants felt that the strength of the relationship may influence client rudeness, and some reported that the rudeness may be acted out to test this relationship and the participant's dedication to it.

Participants provided some important information on how they interpret rudeness. Multiple interviewees stated that any rudeness they experienced should not be taken personally:

"I mean, you are a stranger, they don't know who you are, so it is-it's just anger coming from their personal life, and they're just taking it out on someone because maybe they don't have parents or friend or anyone back home to do that to" $-P 5$

Several participants identified the intentionality of an act of rudeness as important. If the behaviour was caused by the client's mental ill health, participants found it more difficult to class it as rude:

"I do actually struggle to-to find something that really is point blank, deliberately rude, because I do believe that a lot of it is illness, and I don't like to blame behaviour on that at

$$
\text { all" }-P 6
$$

The instigator was also thought of as important. The distinction between colleagues or members of the general public and clients or patients was drawn, with participants stating that these are different types of rudeness, which require different responses. Participants further 
noted that the perception of a behaviour as rude depends on the target, in this case the participant themselves.

Finally, rudeness was discussed in relation to participants' work, with several interviewees reporting that experiencing client rudeness was simply one of their roles in mental health related work:

"I'm somebody who is basically going to be a [metaphorical] punch-bag, a mother-figure, a father-figure, an older sister, a brother, a younger sister.... I'm going to be whatever somebody else needs me to be, and when you're dealing with mental ill health you just-I had to accept that" $-P 6$

\section{Impact of client rudeness}

It was found that client rudeness could have a negative impact in a variety of ways, as seen in Table 4. Several participants identified a negative self-evaluation following rudeness, and noted that rudeness led to negative feelings about their work and their competence in the role: "I was just scared that if it really doesn't work out then they would fire me, or if they don't fire me then I would feel guilty that I am there and they don't know that we are not getting along really well, and then what if I am not actually helping the kid" -P11

Some participants also thought that rudeness could lead to feelings of frustration towards clients, often because they felt that the client was not fully appreciating the work of the service:

"I just find it annoying because there are people trying to get through who need the service, and they're just playing around with it as if it were nothing. " $-P 9$

Not only did client rudeness have a negative emotional impact on participants, but some noted that there was also an effect on their work.

Table 4 here. 
Several participants felt that the negative impact of rudeness could spread to the clients themselves, even those who were not involved in the original incident, either through a disrupted group session, or as an effect of the emotional exhaustion on the participant caused by rudeness.

Some participants discussed a positive impact of client rudeness. Participants felt that rudeness could help their relationship with the client, with some identifying that this was due to the build-up of trust:

"Well after this critical period I believe we were quite close. He really trusted me, I trusted him, we could work together very well." -P11

Additionally, it was suggested that rudeness could support participants' professional development. This appeared to be due to the knowledge, experience, and confidence gained from these interactions:

"Following on from it I felt quite empowered that I was able to diffuse the situation on my own without supervision." $-P 12$

\section{Responding to rudeness}

As seen in Table 5, a wide range of methods for dealing with rudeness were discussed. For example, multiple participants stated that they simply accepted it, and moved forward: "I try to-try to just be as accepting as possible of whatever's going on, and stress or strain or annoyance or frustration or... any of these things and I try not to let those things affect me and just accept it. If somebody doesn't turn up for their appointment and I don't hear from them

$$
\text { then what can you do?" }-P 3
$$

Conversely, non-acceptance methods were also discussed. Several participants stated that they did not allow rude behaviour, and others reported that they may remove themselves from a rude situation by ending the session. This was identified as an important safety measure against escalation. 
Being professional when dealing with rudeness was considered particularly important: "I'm not there to make them like me, I'm there to help them, so if this time she wants to call me the worst names and curse me and whatever...it's her-it's their freedom, like I don't care, I'm there to do my job." $-P 2$

Some noted that this was particularly important to avoid complaints being made to their professional body.

Table 5 here.

Participants highlighted that it was important to keep calm in these situations, often to avoid reflecting the client's negative emotions:

'You've kind of lost if you just kind of-you wouldn't repeat abuse per se but if you kind of show them that you're angered too, it's not helpful." -P5

The extent to which participants believed one should persevere in working with a rude client varied. While some stated that perseverance is essential, others felt that they couldn't always continue to persevere, as this might not always work:

"I think I sort of fell into the trap of thinking if I could just get it right, then I could make it work for her, whereas actually that's a part of what I'm dealing with all the time, that sort of we can't always get it right" $-P 10$

A key point was the fact that their response to rudeness depended on the situation and the client, with one participant giving an example of how their response would vary depending on the mental state of their client:

"So if somebody's, you know, acting out in-in a manic style... and then they do exactly the same thing when they're not manic, it's very likely that when they're not manic I will say to them-I will say to them "This-that's not acceptable". And if they are manic I'll deal with it in

$$
\text { a different way." -P6 }
$$

\section{Coping and support}


Themes discussed relating to coping and support can be seen in Table 6. Some participants identified support as necessary for them and others to carry out their work:

"I think if people didn't feel supported, they wouldn't stay"-P8

However, some did not always rely on this support, and one participant stated that while they did not need support, they did sometimes need to offer support to more junior team members.

Participants identified that there was a variety of support at work that helps them deal with rudeness. In particular, supervision was highlighted as an important source of support, with supervisors being viewed as readily available and proactive in their support. Peer support was also acknowledged as useful in dealing with rudeness and more general workplace concerns:

"I think we're all very supportive of each other and I think every-every time something like that happens is an experience." - P1

In terms of coping and support outside the workplace, self-care and general mental wellbeing activities were discussed. Participants also recognized the importance of talking concerns over with friends and family:

'The really emotional young people who had so much going on, I would kind of discuss with my parents, you know, just kind of get it out further." - P9

Yet this can be problematic for two reasons. Firstly, confidentiality constrains what can be discussed about clients outside the workplace. Secondly, the support and advice from friends and family may not be useful. A further issue discussed was that those in need of support do not always seek it, perhaps because they don't feel comfortable doing so:

“One problem I've definitely noticed is you do a group debriefing session, and there's definitely some counsellors who have really good calls, they've got nothing but something positive to say, but then there's counsellors who are more obviously struggling but I think maybe because if front of a group they weren't comfortable saying it." - P5 
Table 6 here.

\section{Discussion}

The results show that participants experienced a variety of client behaviours they classified as rude, the majority of which were verbal. Common reasons given for these behaviours were the client'spersonal history, mood, and mental health, and as such rudeness was conceptualised as simply a part of working in mental health roles. Furthermore, several factors were discussed as important in interpreting rudeness, including the instigator, the target, and the intentionality of the act. Surprisingly, client rudeness was found to have both negative and positive outcomes on a range of areas including work, client relationships, and participant's feelings towards these aspects. Methods used for dealing with this rudeness appeared to depend on the specific situation, while in terms of coping, participants identified supervisors and colleagues as key sources of support as well as friends and family.

\section{Perception of incivility}

Three main reasons for rudeness were given by participants, including the client's personal history, their illness, and their mood. Interestingly, some of these appear to have been linked to rude and aggressive behaviour by Giesen and colleagues (2008). The researchers report that anxiety, sorrow and pain were reported by $49.7 \%$ of aggressive or rude GP patients. Similarly reported causes of 'difficult' behaviours included mental health and social background (Koekkoek et al., 2011). The current data suggest that the sample were quite accepting of these behaviours, certainly the label of 'difficult' patient was not applied. This may indicate that incivility in isolation is not enough to produce the label of 'difficult', or that multiple behaviours must be observed over time to generate a label of that type.

The current sample reported that uncivil behaviours were more likely at the beginning of the therapeutic relationship, with such behaviours manifesting as a type of test, or because 
of misinterpretations due to lack of familiarity. This suggests that the perception and generation of uncivil behaviours may change as the therapeutic relationship develops over time. This aligns with the idea that the therapeutic alliance is a relationship between therapist and client, with goals and actions that change over time (Locati, Rossi, \& Parolin, 2019). Despite this, a developed relationship may still be subject to 'rupture' where the client and therapist disagree or even argue (Locati et al., 2019), certainly the current sample reported that uncivil behaviours were generally considered 'part of the job' regardless of relationship status.

The finding that rudeness was seen as part of participants' jobs is thought-provoking. It may be that the interviewees preparedness and acceptance mitigate the negative impact of rudeness and assist in managing it. However, it is equally possible that this may lead practitioners to be resigned to experiencing rudeness, and to be less proactive in challenging and preventing such behaviours. This belief also reflected the idea that if rudeness is considered as caused by mental illness, then dealing with rudeness is a part of the participants' role.

\section{Impact of rudeness}

It is perhaps unsurprising that experiencing rudeness led to negative affect for some participants. This is in line with previous research, for example Giumetti et al. (2013), whose research found that working with a rude supervisor led to higher levels of negative affect than working with a supportive supervisor. Participants in the current study also reported negative feelings towards the instigator, and an adverse impact on other clients within group sessions. The former may explain the process behind Khalil's (2009) finding that aggressive patients can be mistreated or ignored by nurses. It may be that experiencing rudeness leads to negative feelings towards the instigator, which in turn leads to the mistreatment of the instigator. 
Findings that showed a positive impact of rudeness on both the participants' relationship with the client and their work were unexpected. An improvement in the relationship with the client may seem counter-intuitive, but aligns with research by Ogan, Finkelstein, Walker, Carlson, and Cassell (2012). They found that in peer tutoring environments, tutees often used face-threat language, which includes insults, challenges, and complaints directed at the tutor. Rather than damaging the relationship, face-threat was associated with increased learning gains for the tutee. It appeared that the face-threat strengthened the relationship between the two individuals. Similarly, Marchiondo and colleagues (2018) found that some targets of incivility could develop 'challenge appraisals' in response to incivility incidents, this involves seeing an incident as something to overcome, and to gain something from rather than a wholly negative event. When targets developed 'challenge appraisals', there was an increase in their job satisfaction and thriving at work (Marchiondo, Cortina, \& Kabat-Farr, 2018). This may explain why some participants felt that rudeness had a positive impact on their work - they may have adopted a 'challenge appraisal' of the experience.

\section{Responding to rudeness}

The variety of methods for dealing with rudeness that participants reported is perhaps explained by the most common theme - that the action taken varies, depending on the situation. This may be why some methods appear to be in direct opposition to each other, for example acceptance and non-acceptance. The importance of controlling one's reaction to rudeness was also expressed, with participants highlighting the need to keep calm and be professional. This is perhaps to control the desire to reciprocate, which has been identified as a common response to incivility (Pearson \& Porath, 2005).

Another popular method of dealing with rudeness was to remove oneself from the situation. This could be in the form of ending the session, or ending contact with the client 
altogether. This has potentially negative ramifications for the patient, similar to the routing out of care reported for 'difficult' patients (Sulzer, 2015). Where the therapeutic relationship is ended the patient would have to begin again with a new provider.

\section{Coping and support}

Participants felt they had a high level of organisational support, especially from supervisors, but also from colleagues, mirroring past research (Jonker et al., 2008). This was a very positive finding, which highlights steps that have already been made to help mitigate the negative impact of some areas of mental health work. Moreover, participants reported that they sought support from friends and family, and that discussing issues with them was helpful. However, confidentiality requirements and a lack of understanding and knowledge on the part of the friend or family member sometimes meant that this was not possible. Thus it is clear that support in the workplace is essential. The importance of organisational and emotional support was also noted by Miner, Settles, Pratt-Hyatt, and Brady (2012), who found that targets of higher levels of incivility reported better well-being when they felt supported both organisationally and emotionally. This further emphasises the close link between support and the impact of rudeness.

\section{Limitations}

This research excluded individuals working in mental health roles within the NHS. As the NHS encompasses such a large proportion of these roles, this overview is incomplete until information is gathered from this sector. Additionally, while the aim was to recruit participants from a wide range of roles and with varying levels of experience, the small number of participants precluded the comparison of these factors. Thus it is still unclear what impact experience has on how rudeness is thought of, dealt with, and coped with. Finally, the use of qualitative methods, while permitting the gathering of rich information, means that 
findings are filtered through the subjective lens of the researchers. Further quantitative research may be necessary to confirm the objectivity of these results.

\section{Practical implications}

The findings of this study have several practical implications. First, participants indicated that staying calm and accepting rudeness as part of the job was an important aspect of learning to cope with that behaviour. In order to enhance coping, and prepare new nurses and practitioners for work, training in emotional intelligence and non-technical skills (Hurley, Hutchinson, Kozlowski, Gadd \& van Worst, 2019) might be helpful. Second, organizational support from supervisors and colleagues is also likely to enhance coping. It is particularly important that discussion is encouraged between colleagues, including sharing good practice, or useful responses to rudeness in this context. Finally, it is important to clarify with new practitioners that rudeness is not always a negative aspect of the therapeutic relationship and can be used to gain additional insight and strengthen the relationship between practitioner and client.

\section{References}

Adams, G. A., \& Webster, J. R. (2013). Emotional regulation as a mediator between interpersonal mistreatment and distress. European Journal of Work and Organizational Psychology, 22(6), 697-710.

Andersson, L. M., \& Pearson, C. M. (1999). Tit for tat? The spiraling effect of incivility in the workplace. Academy of Management Review, 24, 452-471.

Braun, V., \& Clarke, V. (2006). Using thematic analysis in psychology. Qualitative Research in Psychology, 3(2), 77-101. 
Dalenberg, C. J. (2004). Maintaining the safe and effective therapeutic relationship in the context of distrust and anger: Countertransference and complex trauma. Psychotherapy: Theory, Research, Practice, Training, 41(4), 438-447

Duxbury, J., \& Whittington, R. (2005). Causes and management of patient aggression and violence: Staff and patient perspectives. Journal of Advanced Nursing, 50(5), 469478.

Flanagan, J. C. (1954). The critical incident technique. Psychological Bulletin, 51(4), 327.

Giesen, P., Mokkink, H., Hensing, M., van den Bosch, W., \& Grol, R. (2008). Rude or aggressive patient behaviour during out-of-hours GP care: Challenges in communication with patients. Patient Education and Counseling, 73(2), 205-208.

Giumetti, G. W., Hatfield, A. L., Scisco, J. L., Schroeder, A. N., Muth, E. R., \& Kowalski, R. M. (2013). What a rude e-mail! Examining the differential effects of incivility versus support on mood, energy, engagement, and performance in an online context. Journal of Occupational Health Psychology, 18(3), 297.

Han, S. J., Bonn, M. A., \& Cho, M. (2016). The relationship between customer incivility, restaurant frontline service employee burnout and turnover intention. International Journal of Hospitality Management, 52, 97-106.

Hill, C. E., \& Knox, S. (2009). Processing the therapeutic relationship. Psychotherapy research, 19(1), 13-29.

Hurley, J., Hutchinson, M., Kozlowski, D., Gadd, M. \& van Worst, S. (2019). Emotional intelligence as a mechanism to build resilience and non-technical skills in undergraduate nurses undertaking clinical placement. International Journal of Mental Health Nursing, https://doi.org/10.1111/inm.12607.

Horberg, U., Brunt, D. \& Axelsson, A.(2004). Client's perceptions of client-nurse relationships in local authority psychiatric services: A qualitative study. International Journal of Mental Health Nursing, 13, 9-17. 
Inoue, M., Tsukano, K., Muraoka, M., Kaneko, F., \& Okamura, H. (2006). Psychological impact of verbal abuse and violence by patients on nurses working in psychiatric departments. Psychiatry and Clinical Neurosciences, 60(1), 29-36.

Irwin, A., Laing, C., \& Mearns, K. (2013). The impact of patient aggression on community pharmacists: A critical incident study. International Journal of Pharmacy Practice, 21(1), 20-27.

Jonker, E. J., Goossens, P. J. J., Steenhuis, I. H. M., \& Oud, N. E. (2008). Patient aggression in clinical psychiatry: Perceptions of mental health nurses. Journal of Psychiatric and Mental Health Nursing, 15(6), 492-499.

Khalil, D. D. (2009). Nurses' attitude towards 'difficult'and 'good'patients in eight public hospitals. International Journal of Nursing Practice, 15(5), 437-443.

Koekkoek, B., van Meijel, B., \& Hutschemaekers, G. (2006). " Difficult patients" in mental health care: A review. Psychiatric Services, 57(6), 795-802.

Koekkoek, B., Hutschemaekers, G., van Meijel, B., \& Schene, A. (2011). How do patients come to be seen as 'difficult'?: A mixed-methods study in community mental health care. Social Science \& Medicine, 72(4), 504-512.

Kristiansen, L., Hellzén, O., \& Asplund, K. (2006). Swedish assistant nurses' experiences of job satisfaction when caring for persons suffering from dementia and behavioural disturbances. An interview study. International journal of qualitative studies on health and well-being, 1(4), 245-256.

Locati, F., Rossi, G., \& Parolin, L. (2019). Interactive dynamics among therapist interventions, therapeutic alliance and metacognition in the early stages of the psychotherapeutic process. Psychotherapy Research, 29(1), 112-122. 
Marchiondo, L. A., Cortina, L. M., \& Kabat-Farr, D. (2018) Attributions and Appraisals of Workplace Incivility: Finding Light on the Dark Side? Applied Psychology. doi:10.1111/apps. 12127

Miner, K. N., Settles, I. H., Pratt-Hyatt, J. S., \& Brady, C. C. (2012). Experiencing incivility in organizations: The buffering effects of emotional and organizational support. Journal of Applied Social Psychology, 42(2), 340-372.

Needham, I., Abderhalden, C., Halfens, R. J., Fischer, J. E., \& Dassen, T. (2005). Nonsomatic effects of patient aggression on nurses: A systematic review. Journal of Advanced Nursing, 49(3), 283-296.

Nijman, H., Bowers, L., Oud, N., \& Jansen, G. (2005). Psychiatric nurses' experiences with inpatient aggression. Aggressive Behavior, 31(3), 217-227.

Ogan, A., Finkelstein, S., Walker, E., Carlson, R., \& Cassell, J. (2012). Rudeness and rapport: Insults and learning gains in peer tutoring. In Lecture Notes in Computer Science (including subseries Lecture Notes in Artificial Intelligence and Lecture Notes in Bioinformatics)

Pearson, C. M., \& Porath, C. L. (2005). On the nature, consequences and remedies of workplace incivility: No time for "nice"? Think again. The Academy of Management Executive, 19(1), 7-18.

Porath, C. L., \& Erez, A. (2007). Does rudeness really matter? The effects of rudeness on task performance and helpfulness. Academy of Management Journal, 50(5), 11811197.

Sakurai, K., \& Jex, S. M. (2012). Coworker incivility and incivility targets' work effort and counterproductive work behaviors: The moderating role of supervisor social support. Journal of Occupational Health Psychology, 17(2), 150. 
Schilpzand, P., De Pater, I. E., \& Erez, A. (2016). Workplace incivility: A review of the literature and agenda for future research. Journal of Organizational Behavior, $37(\mathrm{~S} 1)$.

Shattell, M. M., Starr, S. S., \& Thomas, S. P. (2007). 'Take my hand, help me out': Mental health service recipients' experience of the therapeutic relationship. International Journal of Mental Health Nursing, 16(4), 274-284.

Sliter, M., Sliter, K., \& Jex, S. (2012). The employee as a punching bag: The effect of multiple sources of incivility on employee withdrawal behavior and sales performance. Journal of Organizational Behavior, 33(1), 121-139.

Sulzer, S. H. (2015). Does "difficult patient" status contribute to de facto demedicalization? The case of borderline personality disorder. Social Science \& Medicine, 142, 8289.

Swanson, J. W. (1994). Mental disorder, substance abuse, and community violence: An epidemiological approach. In J. Monahan \& H. J. Steadman (Eds.), The John D. and Catherine T. MacArthur Foundation series on mental health and development. Violence and mental disorder: Developments in risk assessment (pp. 101-136). Chicago, IL, US: University of Chicago Press.

\section{Acknowledgements}

The authors would like to thank all of the mental health practitioners who gave up their time to participate in this study.

\section{Declaration of interest}

The authors have no conflicts of interest to report. 


\section{Tables}

Table 1.

Number of participants in each role category

\begin{tabular}{lc}
\hline Role & Number of participants \\
\hline Counselling & 6 \\
Clinical psychology & 3 \\
Vocational rehabilitation & 3 \\
Helpline volunteering & 2 \\
Family support & 1 \\
Applied Behavioural Analysis & 1 \\
Psychiatric recovery & 1 \\
Educational psychology & 1 \\
\hline
\end{tabular}


Table 2. Uncivil behaviours reported by mental health practitioners across two main themes: verbal behaviours and disengagement with treatment.

\begin{tabular}{llc}
\hline Theme & Code & $\begin{array}{c}\text { n participants } \\
\text { presenting code }\end{array}$ \\
\hline Verbal behaviours & Complaints about treatment & 8 \\
& Direct verbal incivility & 7 \\
& Uncivil jokes & 4 \\
& Indirect verbal incivility & 3 \\
\hline Disengagement from & Avoidance & 7 \\
therapy & Resisting participation & 6 \\
& Clients withholding information & 3 \\
\hline
\end{tabular}


Table 3. Perception of rude behaviours by mental health professionals across three main themes: perceived rudeness, interpreting rudeness, and accepting rudeness

\begin{tabular}{|c|c|c|c|}
\hline Theme & Sub-theme & Code & $\begin{array}{l}n \text { participants } \\
\text { presenting } \\
\text { code }\end{array}$ \\
\hline \multirow{7}{*}{$\begin{array}{l}\text { Perceived cause } \\
\text { of rudeness }\end{array}$} & \multirow{4}{*}{ Internal } & Personal history & 7 \\
\hline & & $\begin{array}{l}\text { Anger at external } \\
\text { experience }\end{array}$ & 7 \\
\hline & & Emotional / cognitive state & 6 \\
\hline & & Mental health & 4 \\
\hline & \multirow[t]{3}{*}{ Interactional } & Frustration with treatment & 4 \\
\hline & & Establishing relationship & 3 \\
\hline & & Testing boundaries & 2 \\
\hline \multirow{4}{*}{$\begin{array}{l}\text { Interpreting } \\
\text { rudeness }\end{array}$} & \multirow[t]{2}{*}{ Part of the process } & It's not personal & 10 \\
\hline & & Not always intentional & 4 \\
\hline & \multirow[t]{2}{*}{ Perception varies } & Receiver thresholds differ & 6 \\
\hline & & $\begin{array}{l}\text { Instigator influences } \\
\text { perception }\end{array}$ & 4 \\
\hline \multirow{2}{*}{$\begin{array}{l}\text { Accepting and } \\
\text { using rudeness }\end{array}$} & \multirow{2}{*}{$\begin{array}{l}\text { Inherent to mental } \\
\text { health work }\end{array}$} & Part of the job & 7 \\
\hline & & $\begin{array}{l}\text { Rudeness can be } \\
\text { informative }\end{array}$ & 3 \\
\hline
\end{tabular}


Table 4. Perception of the impact of rude behaviours by mental health professionals across five main themes:positive impact, impact on therapeutic process, adverse emotional impact, personal risk, no impact.

\begin{tabular}{lll}
\hline Theme & Code & $\begin{array}{l}\text { n of participants } \\
\text { presenting code }\end{array}$ \\
\hline Positive impact & Helps relationship & 7 \\
& $\begin{array}{l}\text { Professional development } \\
\text { Highlights areas for further } \\
\text { development }\end{array}$ & 6 \\
& $\begin{array}{l}\text { Disruption to group sessions } \\
\text { Emotional exhaustion }\end{array}$ & 3 \\
Impact on therapeutic & 3 \\
process & Wegative feelings about & 5 \\
& Poor self-evaluation & 7 \\
\hline Adverse emotional & Feel upset & 4 \\
response & $\begin{array}{l}\text { Feel frustration towards } \\
\text { client }\end{array}$ & 4 \\
\hline Personal risk & Feel uncomfortable working & 3 \\
& with client & 1 \\
\hline No impact & Feel threatened & 8 \\
& No lingering impact & 3 \\
\hline
\end{tabular}


Table 5. The response of mental health professionals to client rudeness across six main themes: acceptance, non-acceptance, professionalism, control reaction, perseverance and variable response.

\begin{tabular}{llc}
\hline Theme & Code & $\begin{array}{c}\text { n participants } \\
\text { presenting code }\end{array}$ \\
\hline Acceptance & Accept it as part of the process & 8 \\
& Reassure and encourage client & 3 \\
\hline Non-acceptance & Change strategy & 2 \\
& Don't allow behavior & 5 \\
& End situation & 5 \\
\hline Professionalism & Use behavior therapeutically & 9 \\
& Be professional & 8 \\
& Follow standard process of work & 2 \\
& Respond consistently & 2 \\
\hline Control reaction & Keep calm & 6 \\
& Take time before responding & 2 \\
\hline Perseverance & Set limits to perseverance & 4 \\
& Perseverance is key & 2 \\
\hline Variable response & Response depends on client & 7 \\
\hline
\end{tabular}


Table 6. Mental health professional coping strategies for client rudeness in five main themes:

supervisory support, peer support, support outside work, self-support, and poor coping.

\begin{tabular}{llc}
\hline Theme & Code & $\begin{array}{c}\text { n of participants } \\
\text { presenting code }\end{array}$ \\
\hline Supervisory & Gaining insight through talking & 11 \\
support & Always available & 4 \\
& Practical advice & 4 \\
& Supervisor actively seeks opportunity to support & 2 \\
\hline Peer support & Support from colleagues & 8 \\
& Group support & 2 \\
\hline Support outside & Share emotions with friends and family & 7 \\
work & Confidentiality limits support seeking & 3 \\
& Family do not have experience to provide useful support & 2 \\
\hline Self-support & Usual self-care practices & 3 \\
& Utilise additional / enhanced self-care & 6 \\
\hline Poor coping & Disconnect between necessity and support seeking & 3 \\
& Use of alcohol & 1 \\
\hline
\end{tabular}

